\title{
The geostatistical analysis of the atmospheric precipitation in Europe on a West-East line transect
}

\section{Liliana Sîrghea}

"Alexandru.Ioan Cuza" University of Iași, Romania lilas_70@yahoo.com

Keywords: precipitation quantity $\geq 10 \mathrm{~mm}$, summer/winter precipitation ratio, longitude, Europe

\begin{abstract}
The general warming trend of the planet cannot be denied (the average global air temperature has increased by approx. $0.85^{\circ} \mathrm{C}$ between $1880-2012$ (IPCC, 2013). The direct consequence of this warming is an increase in extreme weather events and hence in climate risks. The monitoring and assessing precipitation, identifying the physical laws governing its course in order to be able to estimate and forecast it in the future is therefore of great interest nowadays. Using geostatistical spatial analysis methods, this paper aims at identifying the correlations between longitude and precipitation (due to the specificity of the European climate, given by the major influence of the western circulation) and then an estimation - using linear regression equations - of precipitation amounts depending on longitude. Two variables were calculated for the statistical analysis: the proportion of the mean number of days with precipitation $\geq 10 \mathrm{~mm}$ of the multiannual mean of precipitation days $(\geq 0,1 \mathrm{~mm})$ and the precipitation ratio between the mean precipitation quantities in summer, compared to those in winter (hereinafter referred to as summer/winter precipitation ratio). The geostatistical analysis carried out on a sample of 40 weather stations aligned from west-south-west to east-north-east argues the existence of a strong correlation between longitude and the multiannual mean of days with precipitation $\geq 10 \mathrm{~mm}$ and between longitude and the summer/winter precipitation ratio.
\end{abstract}

\section{Introduction}

The effect of continents and oceans on the weather of a region is well known in the literature in the climate field (Minetti, 1989). Continentality and oceanity indices can only have in view the thermal parameter, or the pluviometric, the thermopluviometric or multi-parameter (complex). In this paper we analysed the position, on a profile on the European continent, of two pluviometric indicators of continentality, the days with a precipitation quantity $\geq 10 \mathrm{~mm}$ and summer/winter precipitation ratio.

The complexity of the factors that influence and modify the spatial and temporal distribution of precipitation on the European continent (western air mass circulation, Gulf Stream, proximity/distance from the ocean, positioning of mountain ranges compared to the predominant western atmospheric circulation), location in different climatic zones, make extremely difficult the identification of the physical forces in their spatial distribution, applicable to the entire European area. The easy access of the wet air masses from the North Atlantic - a strong steam generator due to the Gulf Stream - to the east, is easy, taking place only through the German-Polish Plain.

In order to highlight certain rules for the distribution of the characteristics of significant precipitation $(\geq 10 \mathrm{~mm})$ and the summer/winter precipitation ratio, a line transect (a sample of 40 weather stations) was chosen, on the west-southwest-west to 
east-north-east direction, in the middle part of Europe, from the Atlantic Ocean and passing beyond the Ural Mountains. The profile unfolds in the direction of a large longitudinal extension of the continent, of about $4000 \mathrm{~km}$, from $2^{\circ} \mathrm{W}$ longitude, from Nantes, to $61^{\circ}$ long. $E$, to Ekaterinburg, and between the northern latitudes of $45-50^{\circ}$ in the west of France, and $55-60^{\circ}$, east of Ural Mountains (Fig. 1). Using the geostatistical spatial analysis methods, correlations have been identified between longitude and precipitation quantity $\geq 10 \mathrm{~mm}$ and then an estimate, using the linear regression equation, of the correlations between longitude and the multiannual mean ratio of the days when precipitation quantity is $\geq 10 \mathrm{~mm}$.

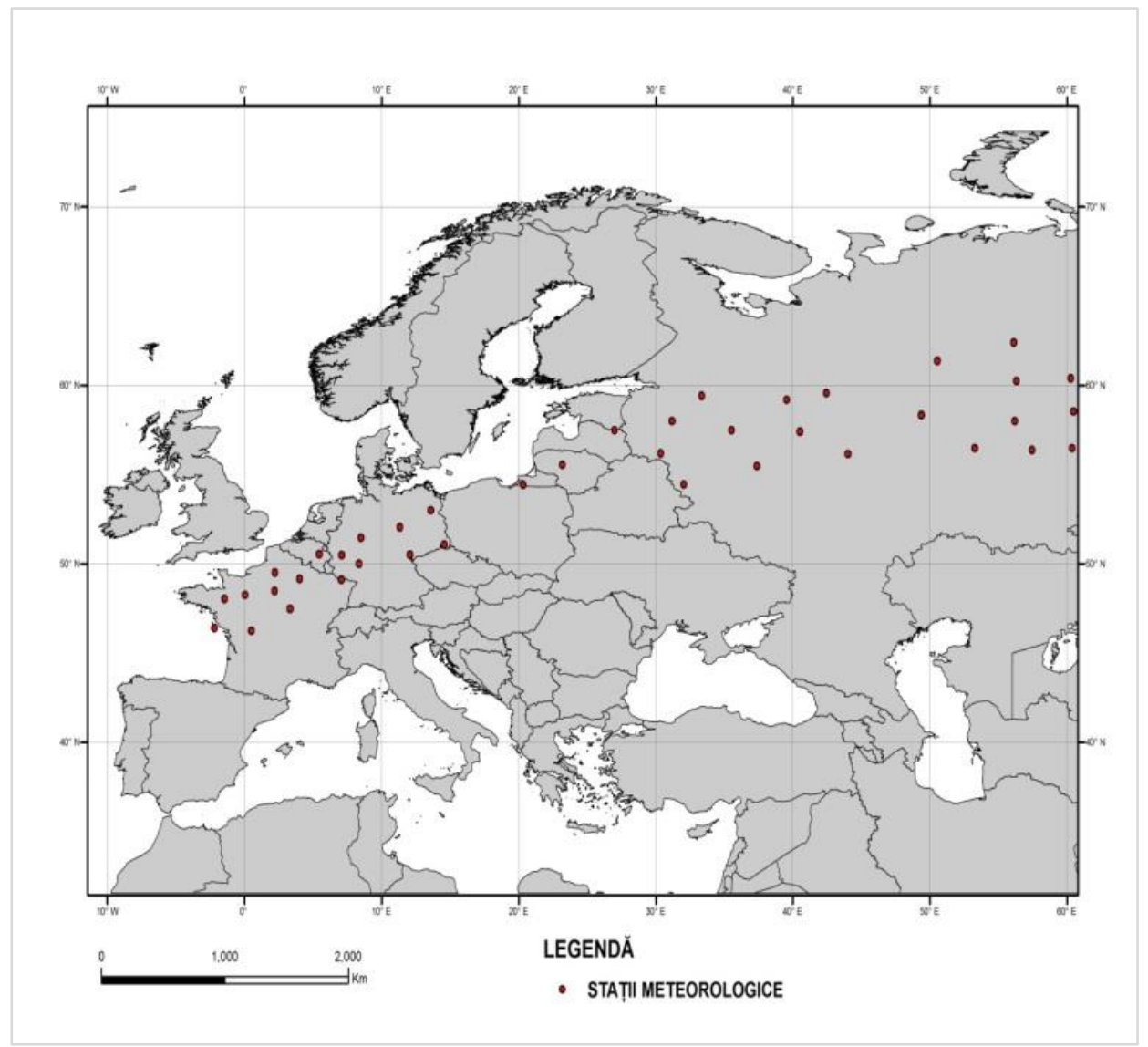

Figure 1. Weather stations in the analysed profile

Precipitation data (monthly means, for the period 1961-2010) were taken from http://eca.knmi.nl (European Climate Assessment $\varepsilon$ Dataset) and processed in a software for open-source statistical calculation (Open Office).

The statistical methods used are mainly according to Groza et al 2003 and Groza 2013, and the works of Rădoane et al 1996, Gaceu 2002, von Storch, Zwiers 2003, Cheval (edit) 2003, Patriche 2009 and Wilks, 2011 were also used.

For the statistical analysis, two quantitative variables (continuous, rate/ratio) were calculated, initially in ascending order according to longitude: the day ratio with precipitation quantity $\geq 10 \mathrm{~mm}$ of the multiannual mean number of days with precipitation $(\geq 0.1 \mathrm{~mm}$ ) the multiannual ratio between precipitation quantity in summer and winter. 
The origin of precipitation in the sector under analysis is predominantly from the North Atlantic, starting at about $74 \%$ in western Europe to $53 \%$ after crossing the Urals (Numaguti, 1999). The number of days with precipitation quantity $\geq 10 \mathrm{~mm}$ is higher in areas with high annual or seasonal mean quantity.

Simple and effective indicators of precipitation continentalism, which have been used for a long time, are precipitation amount and regime. As regards the regime, the ratio between the precipitation quantity in the warm season and in the cold season represent an efficient indicator for determining the continentalism of precipitation, first used by the French climatologist M. Alfred Angot (1906). Angot index determines the seasonal concentration of the mean precipitation quantity as the ratio between the quantities during the hottest 6 months and during the coldest 6 months. In our country, the Angot ratio was analysed for various regions by Stoenescu Șt.M. (1951), Mihai Elena (1975), Bogdan Octavia (1980), and for the entire territory of Romania, in Clima R.P. Române (The climate of the People's Republic of Romania) (1962) and by Apostol L. (1987). In Europe, the regions where April is warmer than October are in the eastern half of the continent. Therefore, the ratio of the two classic semesters, hot (IV-IX) and cold (X-III) is preferred. For the profile analyzed in this paper, a 30-year analysis of this report in Europe indicates values between 0.6 and 2 (Mikolaskova, 2009). With values ranging between 0.5 and 3.3, the ratio between the average amount of summer precipitation, compared to that of winter, on the same profile, in this paper, between 0.5 and 3.3, differentiates even more sharply continentalism and rainfall oceanity.

\section{Data geostatistical analysis}

In a first stage, the modalities of the two variables were grouped into statistical distributions which were later divided into classes and summarized graphically (Groza et al, 2003).

The graph showing the share of days with precipitation amounts $\geq 10 \mathrm{~mm}$, with the number for each class, indicates a multiannual mean with a difference between $5 \%$ and over $13 \%$. Annual values of over $11 \%$ are present at low longitudes (the classes with max. values over $11 \%$ include stations in France and West Germany, but also Kaliningrad in Central Europe) and those below 6 percent/year are situated to the east of the continent (Vologda and Totma, with $6 \%$ annually) and to the east of the Ural Mountains. The stations located beyond the Ural Mountains are classified as having the highest number: Ivdel și Ekaterinburg, with over 7\%), (Fig. 2).

The relative frequency graph shows that $76 \%$ of the analysed stations have percentages between 5 and $10 \%$ for the same variable; in $24 \%$ of cases the variable ranges between $10-13 \%$ (Fig. 2).

The summer/winter precipitation ratio ranges between 0.5 and 3.3 , the highest in number $(40 \%)$ being included in the class $1.7-2.1$. This ratio increases directly proportional to longitude, with precipitation concentrating more and more to the east during summer. Thus, if at France longitude, the summer/winter precipitation ratio approaches or exceeds the unit (meaning that it rains more in winter - 0.5 - or that precipitation is relatively evenly distributed during the year - around 1), from western 
Germany and until the Ural Mountains, in summer rains end up being twice as long as the winter ones, so that at the three stations in the eastern Urals the ratio has values higher than 3. An interesting inversion is revealed by the two stations located $44^{\circ}$ longitude apart from each other: Gera-Leumnitz, in the central-eastern part of Germany (summer/winter ratio over 1.9) and Cherdyn', west of Ural (under 1.5). The reason could be the mountain shelter to the west in the first case and the opening to the western and northern circulations in the second case (Fig. 3).

a)

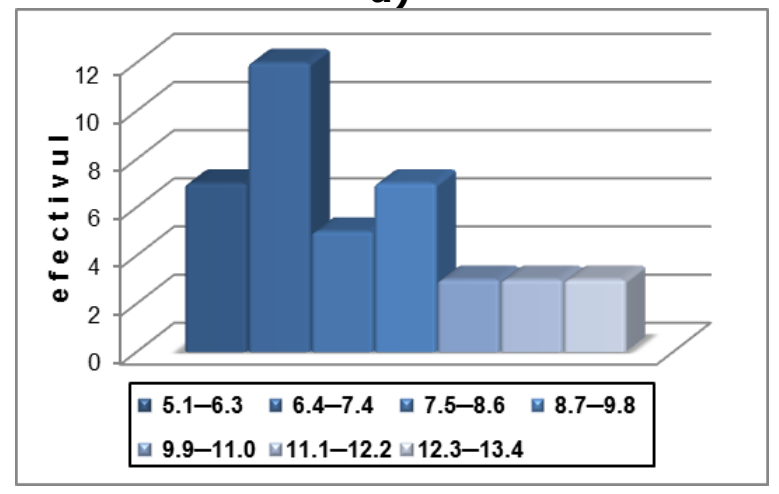

b)

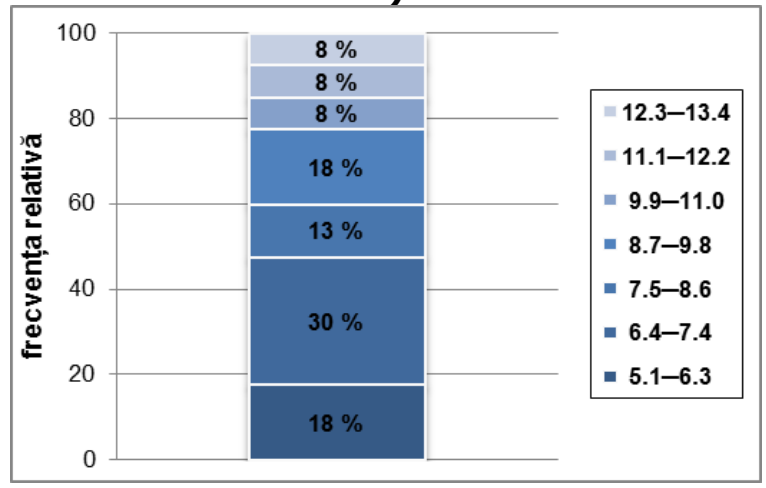

Figure 2. The number (a) and the relative frequency by classes (b) of the share of days with precipitation $\geq 10 \mathrm{~mm} /$ day

a)

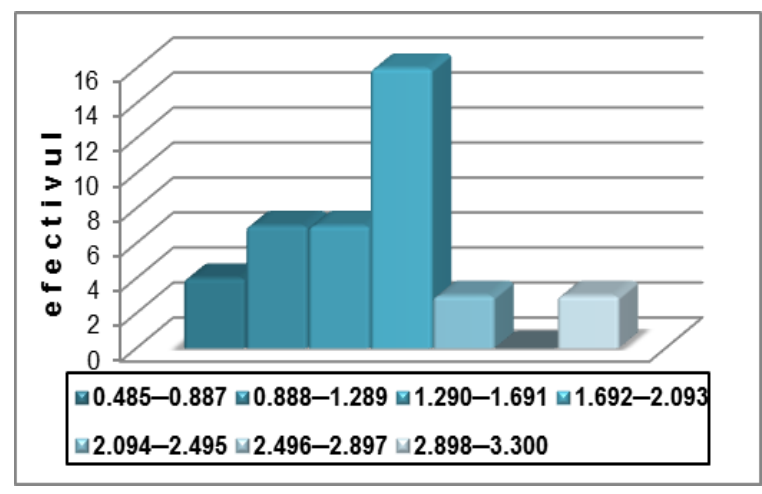

b)

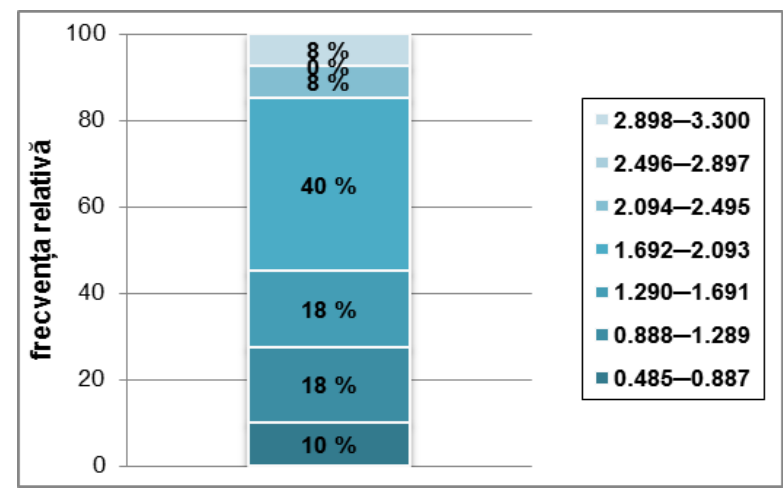

Figure 3. The number (a) and the relative frequency (b) by classes of the summer/winter precipitation ratio

Given that the first variable is a share and the second one is a ratio, the more suitable central value (also called the indicator of central tendency), is the median (Me): 7.6 for the first distribution (the multiannual share of days with precipitation quantity $\geq 10 \mathrm{~mm}$ ) and 1.721 for the second one (summer/winter precipitation ratio), as shown in the graphic representation of the cumulative frequency curves (Fig. 4) (perpendicular of the point of intersection of the two curves on the abscissa).

The absolute dispersion parameters (Groza, 2013) were calculated merely because they will be used in further calculation. However, as the two variables are not identical (the first is a share, and the second is a ratio) and their orders differ in size, the relative dispersion parameters are useful in order to compare the two. The central value on the 
basis of which the relative dispersion indices were calculated is the median, resulting in a higher dispersion (by $5-10 \%$ ) of the values of the summer/winter rainfall ratio, compared to the average multiannual share of days with precipitation $\geq 10 \mathrm{~mm}$ (Table 1 ). Therefore, the summer/winter precipitation ratio is influenced to a greater extent by random factors and therefore the possibility of identifying a physical force through which it can be estimated is much more difficult.

a)

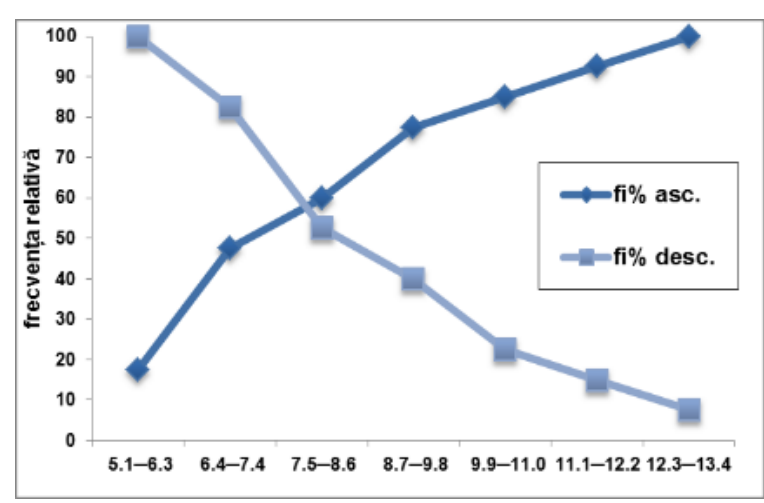

b)

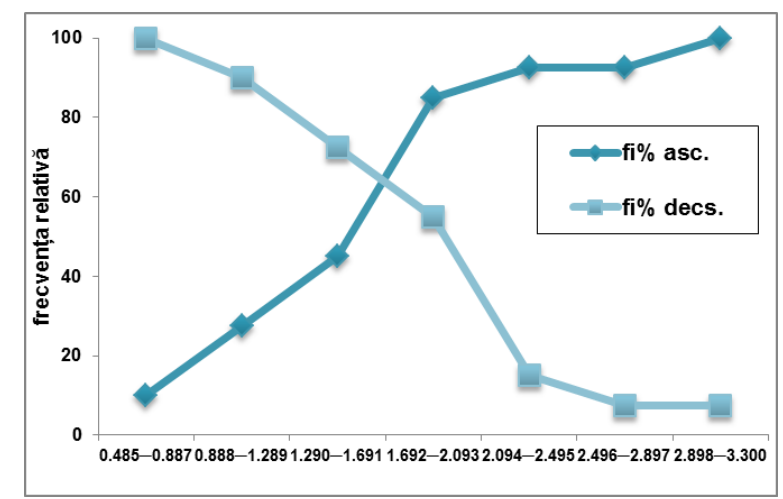

Figure 4. The cumulative frequency curves for the mean share of days with precipitation quantity $\geq 10 \mathrm{~mm}$ and for the summer/winter precipitation ratio

Table 1. Absolute and relative dispersion for the mean ratio of days with precipitation quantity $\geq 10 \mathrm{~mm}$ and for the summer/winter precipitation ratio (SWPR)

\begin{tabular}{|c|c|c|}
\hline relative dispersion indices & $\% \mathbf{> 1 0}$ from $>\mathbf{0 , 1}$ & SWPR \\
\hline \hline $\mathrm{Q}_{3}-\mathrm{Q}_{\mathbf{1}} / \mathrm{Q}_{\mathbf{2}}{ }^{*} 100$ & 35,8 & 47,05 \\
\hline $\mathrm{ea} / \overline{\mathrm{x}}^{*} 100$ & 20,8 & 26,56 \\
\hline $\mathrm{CV}=\sigma / \overline{\mathrm{x}}^{*} 100$ & 27,9 & 36,35 \\
\hline
\end{tabular}

The contingency table shows very clearly that the higher the share of days when precipitation $\geq 10 \mathrm{~mm} /$ day, the lower the summer/winter precipitation ratio (i.e., precipitation is more evenly distributed during the year), and the lower the share of days with precipitation $\geq 10 \mathrm{~mm}$, the higher the summer/winter precipitation ratio (precipitation $\geq 10 \mathrm{~mm} /$ day is concentrated mainly in the warm season, hence the enhanced continentalism and precipitation risk) (Table 2 ).

Standardization/norms means a double conversion, by centring and reduction. By centring, the order of magnitude (central value) of the statistical distribution is brought to a reference value (zero). By centring on 0 , individuals above or below the reference value can be detected immediately (using the +/-- signs). The reduction consists in bringing the dispersion parameter to a second reference value $-1-$, against which (by reporting) the positive or negative differences can be compared, thus considering that the dispersion of each distribution plays the same role in the analysis performed. Thus, it can be described, in a qualitative but objective way, the relative position of individuals 
considering all variables. Since both statistical distributions are bimodal and asymmetric, for a better analysis, their values were centred with respect to the median and reduced with respect to the interquartile range (Table 2 ).

Table 2. Contingency table

\begin{tabular}{|c|c|c|c|c|}
\hline \multicolumn{5}{|c|}{ Me (median) } \\
\hline & SWPR & + & - & \\
\hline \multicolumn{5}{|c|}{$\%>10$ from $>0,1$} \\
\hline+ & & 5 & 16 & 21 \\
\hline - & & 15 & 4 & 19 \\
\hline total & & 20 & 20 & 20 \\
\hline
\end{tabular}

SWPR $=$ the mean summer / winter precipitation ratio $\% \geq 10$ from $\geq 0,1=$ percent $(\%)$ of number of days with precipitation quantity $\geq 10$ $\mathrm{mm}$, from total number precipitation days $(\geq 0,1 \mathrm{~mm})$

The standardized values of the share of days with precipitation $\geq 10 \mathrm{~mm}$ decrease from west to east, being exceptionally high, very high and high to the west of Germany (the most significant values were reported in Saarbrucken, in the west of Germany -2.1in Montmorillon, in the central-western part of France -1.9- or Bad Lippspringe, in the centre-north of Germany -1.7- but also in Kaliningrad, about $20^{\circ}$ longitude to the east, with an exceptionally high value -1.7). Instead, the standardized values for the summer/winter precipitation ratio reports, without exception, very low and exceptionally low values. From Central Europe to the east, the standardized values approaching the mean, small and very small characterize both distributions; only the stations located beyond the Urals mountain range show values of the exceptionally high summer/winter precipitation ratio -1.8 and 1.9 (Table 3 ).

Table 3. Qualitative reading grid of standardized values with respect to the median + the interquartile range)

\begin{tabular}{cc}
\hline standardized value & qualitative significance \\
\hline under -1.0 & exceptionally low \\
from -1.0 to -0.5 & very low \\
from -0.5 to 0.0 & low \\
from 0.0 to +0.5 & medium \\
from +0.5 to +1.0 & high \\
from +1.0 to +1.5 & very high \\
more than +1.5 & exceptionally high \\
\hline
\end{tabular}

Standardization allows the detection of the presence of positive or negative relationships (as in this case), thus representing a preliminary operation mandatory for testing correlations or building value estimation models.

By using correlation, we tried to identify, measure and test some dependency relationships between the analysed statistical distributions: between longitude and the average multiannual mean of days with precipitation $\geq 10 \mathrm{~mm}$, between longitude and 
the summer/winter precipitation ratio and the multiannual mean percentage of days with precipitation $\geq 10 \mathrm{~mm}$ and the summer/winter precipitation ratio. In the first cases, the independent (explanatory) variable is longitude, and in the last case is the multiannual share of days with precipitation $\geq 10 \mathrm{~mm}$ (Fig. 5).
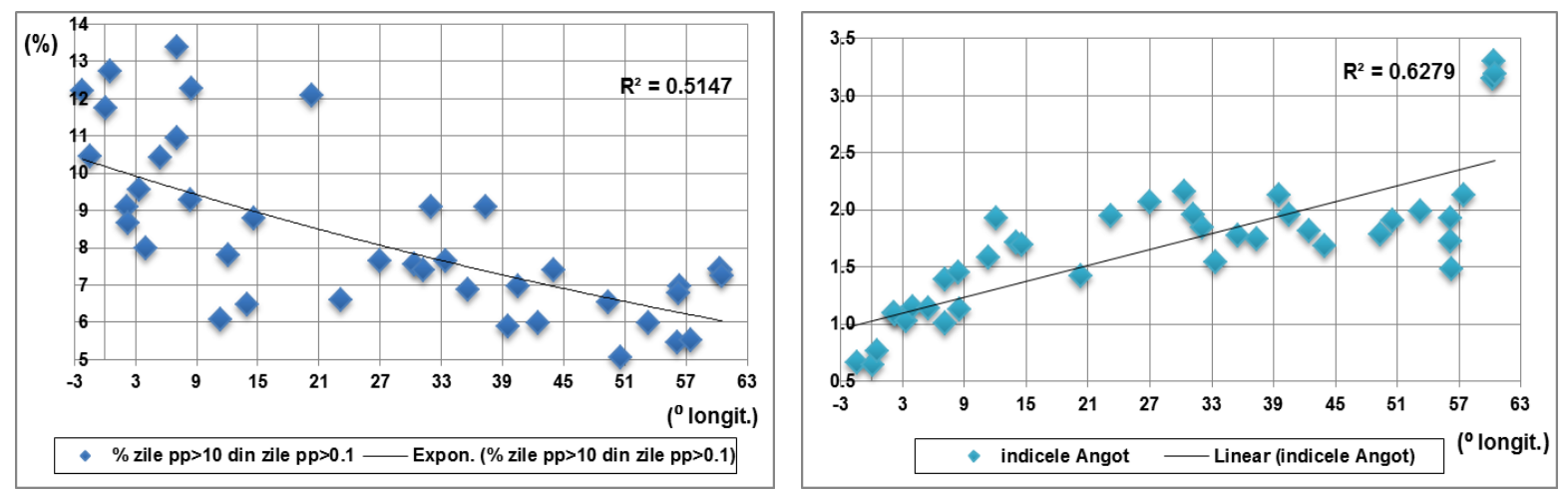

Figure 5. The correlation diagram for the multiannual share of days with precipitation $\geq$ $10 \mathrm{~mm}$ and for the summer/winter precipitation ratio, according to longitude

For both correlation diagrams, the point cloud indicates a weak, nonlinear, but negative relationship in the first case (the share of days with significant precipitation decreases towards the eastern part of the continent) and positive in the second case (precipitation continentalism is accentuated to the east).

The Bravais-Pearson correlation coefficient allows the detection of the presence or absence of a linear relationship between two continuous quantitative characters. For this purpose, first we calculate the covariance (the mean of the product of the differences from the mean):

$$
\operatorname{COV}(X, Y)=\frac{1}{N} \sum_{i=1}^{N}(X i-\bar{X}) *(Y i-\bar{Y})
$$

The linear correlation coefficient is calculated with the relation:

$$
r(X, Y)=\frac{\operatorname{COV}(X, Y)}{\sigma x * \sigma y}
$$

According to the coefficient $r(X, Y)$, calculated on the basis of the median as the central value and the interquartile range as the dispersion parameter, it results as follows:

1. There is a weak negative correlation between longitude and the mean share of days with precipitation $\geq 10 \mathrm{~mm}: r(X, Y)=-0.31$, i.e., the share of days with significant precipitation decreases slightly with increasing longitude;

2. The corelation between longitude and the summer/winter precipitation ratio is weak, but positive: $r(X, Y)=+0.32$, i.e., summer rainfall increases slightly to the east;

3. There is a negative and weak correlation between the mean multiannual share of days with precipitation $\geq 10 \mathrm{~mm}$ and the summer/winter precipitation ratio (when the median is used): $r(X, Y)=-0.42$, up to strong (when using the arithmetic mean): $r(X, Y)=-\mathbf{0 . 6 1}$. 
The conclusions resulting from the low values of the linear correlation coefficients could be erroneous, due to the fact that the statistical distributions under analysis are nonlinear (the point cloud highlights a curvilinear shape which adjusts poorly to a straight line). For this reason, the Spearman correlation coefficient is more useful, based on researching the ranks between the attributes of individuals:

$$
\rho(X, Y)=1-\frac{6 * \sum_{i=1}^{N}[R(X)-R(Y)]^{2}}{N^{3}-N}
$$

For the three statistical distributions, the following values of the Spearman rank correlation coefficient were obtained:

1. Between longitude and the multiannual mean of days with at least $10 \mathrm{~mm}$ of precipitation: -0.73 (strong, but negative correlation)

2. Between longitude and the summer/winter precipitation ratio $\mathbf{+ 0 . 8 1}$ (positive and strong correlation)

3. Between the multiannual mean of the days with at least $10 \mathrm{~mm}$ precipitation and the summer/winter precipitation ratio-0.69 (strong negative correlation).

The fact that the values of the Spearman coefficient maintain the sign confirms the results obtained when calculating the Pearson-Bravais coefficient, and the higher absolute values of the Spearman correlation coefficient suggest the existence of a nonlinear relationship between pairs of variables, this hypothesis is validated also by the correlation diagrams (Table 4).

Table 4. Pearson - Bravais and Spearman correlation coefficients

\begin{tabular}{|c|c|c|c|}
\hline correlation coefficients & $\mathbf{1}$ & $\mathbf{2}$ & $\mathbf{3}$ \\
\hline \hline $\mathrm{r}(\mathrm{X}, \mathrm{Y})$ & $-0,31$ & 0,32 & $-0,42$ \\
$\sigma(X, Y)$ & $-0,73$ & 0,81 & $-0,69$ \\
\hline
\end{tabular}

To validate the results obtained from the calculation of the Pearson-Bravais and Spearman coefficients, it is necessary to test the significance of the relations. According to Table 5 it can be stated, with an error margin less than $5 \%$, that the calculated relations are not due to random factors.

Table 5. Statistical significance of the Pearson-Bravais linear correlation coefficient (a) of the rank-correlation Spearman coefficient (b)

a)

\begin{tabular}{|c|c|c|c|}
\hline & first correlation & second correlation & third correlation \\
\hline $\operatorname{Ir}(\mathrm{X}, \mathrm{Y}) \boldsymbol{I}$ & 0.31 & 32 & 0,42 \\
\hline $\mathrm{r}(\alpha, \mathrm{N})$ for $\alpha=5 \%$ & 0.3044 & 0.3044 & 0.3044 \\
\hline significance & correlation & correlation & correlation \\
\hline $\mathrm{r}(\alpha, \mathrm{N})$ for $\alpha=1 \%$ & 0,3578 & 0,3578 & 0,3578 \\
\hline significance & no correlation & no correlation & correlation \\
\hline
\end{tabular}

b)

\begin{tabular}{|c|c|c|c|}
\hline & first correlation & second correlation & third correlation \\
\hline $\operatorname{|r}(\mathrm{X}, \mathrm{Y}) \mid$ & 0.73 & 0,81 & 0,69 \\
\hline $\mathrm{r}(\alpha, \mathrm{N})$ for $\alpha=5 \%$ & 0,26 & 0,26 & 0,26 \\
\hline significance & correlation & correlation & correlation \\
\hline $\mathrm{r}(\alpha, \mathrm{N})$ for $\alpha=1 \%$ & 0,37 & 0,37 & 0,37 \\
\hline significance & correlation & correlation & correlation \\
\hline
\end{tabular}


However, for a $1 \%$ risk of error, only the correlation between the mean share of days with a precipitation quantity $\geq 10 \mathrm{~mm}$ and for the summer/winter precipitation ratio is confirmed. For the Spearman coefficient (see Table 6), all other correlations are validated with less than $1 \%$ risk of error.

In conclusion, longitude strongly influences both the mean annual share of days with a precipitation quantity $\geq 10 \mathrm{~mm}$ (decreasing) and the summer/winter precipitation ratio (precipitation amounts are concentrated in the summer season as it moves towards east). Also, as the number of days with significant amounts of precipitation ( $\geq 10 \mathrm{~mm}$ ) increases, the precipitation continentalism is enhanced (rains are concentrated during one season) and, as a consequence, the hydrological risk appears.

The regression method aims at finding the dependence of one character with respect to the other and allows the building of a predictive model, it being assumed that by knowing one of the variables (independent variable), the values of the other variable (dependent variable) can be estimated.

Assuming that the independent variable is the longitude, and the dependent variable is the annual mean share of days with precipitation $\geq 10 \mathrm{~mm} /$ summer/winter precipitation ratio, the optimal values for adjusting the regression line parameters (a - Y's rate of variation according to $X), b-Y^{\prime} s$ value for $X=0$ ) were calculated using the following formulas:

$$
\begin{gathered}
a=\frac{\operatorname{COV}(X, Y)}{(Q 3-Q 1)^{2}}, \\
b=\operatorname{Me}(X)-a * \operatorname{Me}(Y)
\end{gathered}
$$

Table 6. Equations of the regression line

\begin{tabular}{ccc}
\hline Crt.no. & $\mathbf{a X + b}$ & $\mathbf{r}(\mathbf{X}, \mathbf{Y})^{\mathbf{2}}$ \\
1. & $Y=-0,0211 * X+8,2119$ & 0.10 \\
2. & $Y=0,0065 * X+1,5308$ & 0.10 \\
3. & $Y=-0,162 * X+3,014$ & 0.37 \\
\hline
\end{tabular}

For the first correlation (1) - between longitude and the multiannual mean share of days with precipitation $\geq 10 \mathrm{~mm}$ - only $10 \%$ of the values could be estimated using the equation of the regression line (see Tab. 6). The stations located at low longitudes (until approx. $10^{\circ} \mathrm{E}$ ) report real percentages of the multiannual means of days with precipitation $\geq 10 \mathrm{~mm}$, much more than the ones estimated with the regression equation (Saarbrucken: $+5 \%$, Montmorillon: $+5.5 \%$, Bad Lippspringe: $+4 \%$ ). Starting with the central-eastern part of Germany and up to the longitude of the Urals, the real values are below the estimated ones (the three stations located beyond this mountain range have values of up to $0.5 \%$ above the theoretical ones). The most significant exception is Kaliningrad, with a positive difference compared to the estimated value of more than $4 \%$ (similar to those at $0-1^{\circ} \mathrm{E}$ longitude). Further east, values above the estimated ones are Moscow $(+1.7 \%)$ or Smolensk $(+1.6 \%)$. Values well below estimated were recorded in Syktyvkar $(-2.1 \%)$, in the east of the Russian Plain, and in Krasnoufimsk $(-1.5 \%)$. 
As a result, very high positive differences between the calculated theoretical values of days with significant precipitation ( $\geq 10 \mathrm{~mm}$ ) and the actual ones recorded in Western Europe (hence the difficulty of forecasting them) could generate risks related to heavy rainfall and flooding (increasingly common in the western part of the European continent). To the east, the differences - generally above or below $1 \%$ - will create lower risks.

The second correlation (2) between longitude and the summer/winter precipitation ratio (at an equally low coefficient of determination -10\%) the deviations from the values estimated by the regression equation are between +1 and -1 , generally keeping the same tendency. The real values lower than those calculated by the regression equation at low longitude have their explanation in the oceanic influence, which makes the rainfall to be distributed relatively evenly throughout the year. To the east, due to the distance from the ocean, precipitation is increasingly concentrated in the warm season, generating the continentalization of the climate - the summer/winter precipitation ratio records real values over the estimated ones. In the central-western part of Russia, the real values are closest to the calculated ones, with differences increasing to the east (the stations west of the Urals record the highest positive differences: between +1.2 and 1.4). Again, Kaliningrad stands out ( 0.25 less than the calculated ratio) or Tikhvin, east of Petersburg ( 0.2 below the estimated value). Nevertheless, the values above the estimated ones regarding the summer/winter precipitation ratio present from the east of Germany (de la $12^{\circ}$ east longitude) are an argument of the presence of continental influences in the distribution of precipitation, far to the west.

The third (3) correlation between the mean share of days with precipitation $\geq 10 \mathrm{~mm}$ and the summer/winter precipitation ratio, the possibility to estimate values based on the linear regression equation is higher (the coefficient of determination is $37 \%$ ); in this case, the correlation is more significant, the linear correlation coefficient is -0.61 (when $\overline{\mathrm{x}}$ was used as the central value and the interquartile range (Q3 - Q1) as the dispersion parameter). Real values, much lower than the ones calculated for the summer/winter precipitation ratio at low longitudes (until approximately 10-120 east) are due to the western circulation, and the days with important quantity of precipitation are thus distributed on a wider time range, therefore reducing risks. The exception is represented by the stations: Gera-Leumnitz ( +0.170$)$, Saarbrucken $(0.162)$, Köln-Bonn (0.150) and Bad Lippspringe (0.104). Located near mountain ranges (which contribute to significant shares of days with precipitation $\geq 10 \mathrm{~mm}$ ), the concentrating tendency of days with rainfall over $10 \mathrm{~mm}$ in the warm season can generate hydrological risks. Between 15o 420 eastern longitude (form the West of Germany to the south of the lakes Ladoga and Onega, the summer/winter precipitation ratio has real values higher than the estimated ones, showing the continentalization of the climate to the east. The most significant positive differences are recorded by the stations located south and east of the Baltic Sea: Kaliningrad (+0.359), Velikie Luki (+0.364), Vöru (+0.294), Smolensk (0.300). On this longitudinal area, values lower than the calculated ones are recorded at the two stations located south of the lakes Ladoga and Onega (which moderate continentalism): Tihvin (0.235) and Maksatiha (-0.123). Furthermore, up to the eastern limit of Europe, the summer/winter precipitation index shows values below the estimated ones, and at the 
stations located beyond the Ural mountain range it has the biggest differences compared to the calculated values (between +1.35 and +1.50 ), thus showing an accentuated continentalism.

\section{Conclusions}

Using geostatistical spatial analysis methods, this paper aims at identifying the correlations between longitude and precipitation (due to the specificity of the European climate, given by the major influence of the western circulation) and then an estimation - using linear regression equations - of precipitation amounts depending on longitude. To perform the statistical analysis, two variables were calculated: the proportion of days with significant amounts of precipitation ( $\geq 10 \mathrm{~mm}$ ) in the multiannual mean number of days with precipitation ( $\geq 0.1 \mathrm{~mm}$ ) and the summer/winter precipitation ratio.

The share of days with precipitation amounts $\geq 10 \mathrm{~mm}$ has a multiannual average with a difference between $5 \%$ and over $13 \%$, while the summer/winter precipitation ratio includes values between 0.5 and 3.3 , both variables increasing directly proportional to the longitude.

Given that the first variable is a share and the second one is a ratio, the more suitable central value is the median (Me): 7.6 for the first distribution (the multiannual share of days with precipitation quantity $\geq 10 \mathrm{~mm}$ ) and 1.721 for the second one (summer/winter precipitation ratio).

The analysis of the relative dispersion parameters shows that the summer/winter precipitation ratio is influenced to a greater extent by random factors and therefore the possibility of identifying a physical force through which it can be estimated is much more difficult. Next, the contingency and standardization table reveal (albeit qualitatively) an inverse dependence between the two variables. The point cloud of the correlation diagram highlights the existence of weak, nonlinear relationships between variables.

Low values of the Bravais - Pearson linear correlation coefficients were obtained (between -0.31 and -0.61 ), but significant values resulted for the Spearman correlation (from -0.69 to +0.81 , also with a higher statistical significance). The equation of the linear regression line can estimate a weight between 10 and $37 \%$ of the sample values. The nonlinear regression, more appropriate in the case of the analysis of the precipitation distribution (and which will be the subject of a future research) could estimate the precipitation values to a higher percentage.

\section{References}

1. Angot, A. (1906). Étude sur le régime pluviométrique de la Méditerranée, C. R. Congr. Soc. Sav. Paris, p. 120-134.

2. Apostol, L. (1987), Considerații privind raportul dintre cantitățile semestriale de precipitații din România, Lucr. Seminar. Geograf. "D. Cantemir", nr. 7/1986, Univ. "Al.I. Cuza", Iași.

3. Bogdan, Octavia (1980), Potențialul climatic al Bărăganului, Edit. Academiei, București.

4. Cheval, S. (editor), (2003), Indici și metode cantitative utilizate în climatologie, Editura Universității din Oradea.

5. Gaceu, O. (2002), Elemente de climatologie aplicată, Editura Universității din Oradea

6. Groza, O., Grasland, C., Apetrei, M. (2003), Elemente de statistică geografică, Editura Universității "Al. I. Cuza", Iași. 
7. Groza, O. (2013), Statistică și analiză de date. Metode de analiză statistică spațială în organizarea și amenajarea teritoriului, curs, Universitatea" Al. I. Cuza", Iași.

8. Mikolaskova, Katerina (2009), Continental and oceanic precipitation regime in Eurrope, Cent. Eur. J. Geosci., 1(2) 176-182, DOI: https://doi.org/10.2478/v10085-009-0013-8, Springer Nature Switzerland AG.

9. Mihai, Elena (1975), Depresiunea Brașov. Studiu climatic,Edit. Academiei, București.

10. Minetti, J.L. (1989), Continentality indices. Methodology revision and proposition, Erdkunde, band 43, Un iversity of Bonn, http://www.jstor.org/stable/25645336.

11. Namaguti, A. (1999), Origin and recycling processes of precipitating water over the Eurasian continent: Experiments using an atmospheric general circulation model, Journal of Geophysical Research, vol. 104, No D2, pg. 1957-1972, January, American Gophysical Union, Washington D.C.

12. Rădoane, Maria et al (1996), Analiza cantitativă în geografia fizică, Editura Universității "Al. I. Cuza" Iași.

13. von Storch, H., Zwiers, F.W. (2003), Statistical Analysis in Climate Research, Cambridge University Press (Virtual Publishing).

14. Patriche, C.V. (2009), Metode statistice aplicate în climatologie, Editura Terra Nostra, Iași.

15. Stoenescu, Șt.M. (1951), Clima Bucegilor, Memorii și Studii, D.G.H., I.M.C., Edit. Tehnică, București.

16. Wilks, D. (2011), Statistical Methods in the Atmospheric Sciences, Elsevier Science Publ. Co Inc, Academic Press Inc, San Diego.

17. ***(1962), Clima R. P. Române, vol. I, C.S.A., I.M., București.

18. ***(2013), Climate change 2013. The Physical Science Basis, IPCC - Intergovernmental Panel on Climate Change, Working Group I contribution to the Fifth Assessment Report, Cambridge University Press.

19. http://eca.knmi.nl/ Climate Assessment \& Dataset website.

(c) 2021 by the authors. Licensee UAIC, Iasi, Romania. This article is an open access article distributed under the terms and conditions of the Creative Commons Attribution (CC BY-NC-ND) license (https://creativecommons.org/licenses/by-nc-nd/4.0). 